\section{Estetik}

Jurnal Bahasa Indonesia
Institut Agama Islam Negeri (IAIN) Curup, Indonesia

ISSN 2622-1810 (p); 2622-1829 (e)

volume 4, number 1, 2021 | page: 17-36

DOI: http://doi.org/10.29240/estetik.v4i1.2197

\title{
Analisis Wacana Kritis Pada Debat Pilwakot Surakarta Putaran Kedua Tahun 2020
}

\author{
Indah Wahyuningsih \\ Institut Agama Islam Negeri (IAIN) Surakarta, Indonesia \\ Indahwahyu30112000@gmail.com
}

\begin{abstract}
This study aims to describe the discourse analysis contained in the second round of the Surakarta pilwakot debate in 2020. In a critical discourse analysis study, the debate can be analyzed using William L. Benoit's functional theory which includes acclaims or claims, attacks or attacks, and defends or defends. This research uses descriptive qualitative research by describing the functional theory contained in the second round of the Surakarta Pilwakot debate. The documentation technique was used to collect data by watching, viewing, and writing the most important points in the second round of the Solo Pilwakot debate live video broadcast. Content analysis techniques were used in this study to obtain the forms of acclaim, attacks, and defends used by candidate pairs in arguing. Based on the results of the analysis, the two pairs of candidates equally made acclaims or claims, recognition as one way to convince their supporters. As for attacks or attacks, candidate pair number 1 is superior in attacking candidate pair number 2. On defends, candidate pair number 1 (Gibran-Teguh) defends based on empirical data or facts as an aspect of knowledge which supports his argument. Another case with candidate pair number 2 (Bagyo-Supardjo) who is not strong enough in doing a defense or defends through answers or responses that are out of the context in question.
\end{abstract}

Keywords: Debate, Functional Theory, Discourse Analysis

Abstrak. Penelitian ini bertujuan untuk mendeskripsikan analisis wacana yang terdapat pada debat pilwakot Surakarta putaran kedua tahun 2020. Dalam kajian analisis wacana kritis, debat dapat dianalisis menggunakan teori fungsional William L Benoit yang meliputi acclaims atau mengklaim, attacks atau menyerang, dan defends atau bertahan. Penelitian ini menggunakan jenis penelitian deskriptif kualitatif dengan mendeskripsikan teori fungsional yang terdapat pada debat pilwakot Surakarta putaran kedua. Teknik dokumentasi digunakan untuk pengambilan data dengan cara menonton, melihat, dan menulis pokok-pokok terpenting pada video siaran langsung debat Pilwakot Surakarta putaran kedua. Teknik analisis isi digunakan dalam penelitian ini untuk mendapatkan bentuk-bentuk acclaims, attacks, dan defends yang digunakan pasangan calon dalam berdebat. Berdasarkan hasil analisis, kedua pasangan calon secara seimbang melakukan acclaims atau pengklaiman, pengakuan sebagai salah satu cara untuk meyakinkan pendukungnya. 
Sedangkan attacks atau serangan, pasangan calon nomor urut 1 lebih unggul dalam melakukan penyerangan terhadap paslon nomor urut 2. Pada defends atau pertahanan, pasangan calon nomor urut 1 (Gibran-Teguh) melakukan defends dengan didasari data atau fakta yang empiris sebagai salah satu aspek pengetahuan yang mendukung argumentasinya. Lain halnya dengan paslon nomor urut 2 (Bagyo-Supardjo) yang kurang kuat dalam melakukan suatu pertahanan atau defends melalui jawaban atau responnya yang keluar dari konteks yang dipertanyakan.

Kata Kunci: Debat, Teori Fungsional, Analisis Wacana

\section{Pendahuluan}

Bahasa dan wacana memiliki hubungan yang saling berkesinambungan. Wacana termasuk antarbagian dalam sebuah bahasa, yang berupa teks, tulisan, tuturan, dan lain-lain.Menurut Harimurti Kridalaksana dalam (Mustofa, 2010: 8)mengartikan bahwa wacana merupakan satuan bahasa terlengkap; dalam hierarki gramatikal merupakan satuan gramatikal tertinggi atau terbesar. Dia menegaskan hal yang paling penting dalam wacana adalah keutuhan atau kelengkapan maknanya. Adapun bentuk konkretnya dapat berupa kalimat, kata, paragraf, karangan utuh.

Analisis wacana kritis melihat bahasa digunakan untuk melihat ketimpangan kekuasaan yang terjadi dalam masyarakat. Analisis wacana kritis menyelidiki dan berusaha membongkar bagaimana penggunaan bahasa oleh kelompok sosial saling bertarung dan berusaha memenangkan pertarungan ideologi tersebut (Fauzan, 2014). Analisis wacana tidak hanya memahami wacana semata-mata sebagai suatu studi bahasa, namun analisis wacana kritis juga menghubungkannya dengan konteks. Konteks yang dimaksud adalah konteks praktik kekuasaan yang bertujuan untuk memarginalkan individu atau kelompok tertentu melalui penggunaan kekuasaan dalam memproduksi teks (wacana) (Fauzan, 2013). Pada studi analisis wacana kritis digunakan untuk mengetahui fenomena kebahasan yang terdapat dalam sebuah wacana.

Serupa dengan hal di atas, wacana dan politik tidaklah dapat dipisahkan dengan bahasa. Politik bermula dari tindakan dan bahasa, baik bahasa verbal, non-verbal, literal hingga audio visual yang diekspresikan oleh manusia dalam kehidupan keseharian. Pada dasarnya setiap manusia mewarisi kode bahasa yang digunakan dalam ekspresi 
keseharian, baik melalui medium tubuhnya, maupun melalui medium lain diluar anggota tubuhnya (Ahmad, 2012). Penggunaan bahasa yang digunakan dalam dunia politik bertujuan untuk menarik simpati maupun menarik perhatian masyarakat.

Indonesia menganut sistem pemerintahan demokrasi yang berlandaskan "dari rakyat, oleh rakyat, dan untuk rakyat". Adanya sistem pemerintahan demokrasi memberikan ruang untuk rakyat dalam menuangkan aspirasinya.Demokrasi memang memberikan hak bagi siapapun yang ingin menyampaikan aspirasinya sekalipun dengan menggunakan dan memanfaatkan kekuatan-kekuatan politik untuk mengkonsololidasikan diri dan memanfaatkan kampanye sembari mendendangkan dengan menyajikan ilusi-ilusi spektakuler (Istiqomah, 2004). Dengan hal ini, seluruh rakyat dapat ikut serta memerintah dengan perantara, yaitu wakil rakyat.

Terselenggaranya sebuah sistem pemerintahan demokrasi terbukti dengan adanya pemilihan umum yang digelar serentak di seluruh Indonesia. Dalam konteks kehidupan politik demokrasi, pemilu dan pilkada merupakan salah satu sarana untuk mewujudkan kehidupan politik yang demokratis (Purnaweni, 2004). Sudah menjadi rahasia umum bahwa terselenggaranya pemilu selalu diiringi oleh pesta rakyat, seperti adanya kampanye maupun debat publik yang disiarkan di beberapa televisi nasional.

Sejak abad ke-5 sebelum Masehi, Athena telah menerapkan sistem demokrasi menggunakan teknik debat. Berbagai sumber menyebutkan bahwa sistem demokrasi dan perdebatan di Polis Athena bisa terlihat dalam teks-teks konstitusi Athena dari Sekolah Aristoteles serta karya sejarawan Yunani seperti Herodotus, Thucydides, dan Xenophon (Sudrajat, 2010). Dalam konteks ketatanegaraan, berdebat menjadi praktik yang dianut berbagai sistem pemerintahan. Beberapa negara pun menekankan musyawarah mufakat yang mana setiap individu perlu menyampaikan argumennya dalam sebuah forum. Menurut (Pratama et al., 2019) debat diartikan sebagai kegiatan adu argumenasi antara dua pihak atau lebih (perorangan atau kelompok) yang berusaha mendiskusikan dan memutuskan masalah serta mengkaji perbedaan mengenai sebuah permasalahan. 
Teknik argumentasi digunakan sebagai landasan dalam berdebat. Hal ini bertujuan agar penyampaian pendapat lebih terstruktur dan logis, mengingat bahwa dalam kehidupan bermasyarakat banyak sekali perbedaan pendapat antara manusia satu dengan manusia yang lainnya. Namun, ilmu dalam berdebat perlu dikuasai oleh beberapa manusia untuk menghindari beberapa stigma negatif dalam berdebat. Stigma negatif tersebut melekat pada diri seorang debater yang mengutamakan ego, memaksakan pendapatnya sendiri, dan bahkan debater yang mengajarkan hal-hal di luar norma masyarakat (Pratama et al., 2019).

Dengan adanya pemilu, menghadirkan debat publik yang ditunggu-tunggu oleh masyarakat umum. Debat publik menjadi salah satu alternatif kampanye yang menarik di era modernisasi saat ini, yang mengedepankan media massa sebagai pusat informasi. Pada setiap pertunjukan debat politik akan terjadi beberapa peristiwa di luar dugaan penonton, hal inilah yang seringkali membuat situasi debat menjadi menantang dan panas dengan kehadiran dua pasangan calon yang beradu argumentasi. Penyampaian argumentasi setiap individu tidaklah selamanya akan menggunakan bahasa yang baik, terlebih dalam situasi debat yang dapat saling menyudutkan dan saling ngotot dalam mempertahankan argumentasinya. Telah diketahui bersama bahwa terdapat berbagai macam debat politik yang ada di Indonesia, namun peneliti sangat tertarik dengan debat pilwakotSolo. Hal ini dikarenakan terdapat beberapa teknik argumentasi yang diciptakan oleh pasangan calon yang menuai percekcokan sehingga menjadi pemberitaan panas di media massa.

Pasangan calon walikota dan wakil walikota Solo yaitu Gibran Rakabuming dan Teguh Prakoso, melawan Bagyo Wahyono dan F. X. Supardjo telah selesai melakukan kampanye dengan berbagai teknik, salah satunya adalah debat publik yang diselenggarakan dua kali putaran di media televisi. Debat publik tersebut menuai berbagai macam komentar, pasalnya putra pertama Presiden Republik Indonesia, Jokowi yang menjadi salah satu calon walikota Surakarta. Berbagai anggapan telah tersebar di media massa mengenai putra pertama Jokowi yang ikut serta dalam pemilihan umum walikota Surakarta, yang mana kota merupakan kota kelahiran Jokowi. Debat pilwakotSurakarta ditayangkan 
di beberapa stasiun televisi secara live dan diunggahnya ke Youtube. Debat pada putaran kedua berlangsung sangatlah sengit dengan para pasangan calon walikota yang saling menyindir dengan bahasa khasnya tersendiri.

Penelitian yang serupa dengan penelitian ini, pernah dilakukan oleh (Simanjuntak \& Salem, 2017) dengan judul "Analisis Wacana Kritis Debat Publik Pilkada DKI Jakarta Putaran kedua Tahun 2020". Hasil penelitian tersebut menganalisis mengenai aspek-aspek bahasa yang mengandung unsur kuasa dan ideologi pada tuturan calon Gubernur DKI Jakarta yang terdapat pada kosakata, gramatika, dan struktur teks. Persamaan dari penelitian tersebut adalah sama-sama mengkaji mengenai debat pilkada melalui analisis wacana kritis. Perbedaannya terletak pada objek yang digunakan sebagai penelitian dan teknik analisis data yang digunakan. Jika pada penelitian tersebut objeknya adalah debat pilkada DKI Jakarta putaran kedua tahun 2017 dengan menggunakan teori analisis wacana kritis Norman Fairclough sebagai analisis data, sedangkan objek pada penelitian ini adalah debat pilwakotSoloputaran kedua tahun 2020 dengan menggunakan teori fungsional William L Benoit. Simpulan dari penelitian yang telah dilakukan (Simanjuntak \& Salem, 2017) berupa (1) Deskripsi aspek-aspek bahasa yang mengandung unsur kuasa dan ideologi dalam tuturan kedua calon gubernur DKI Jakarta yang terdapat pada kosakata, gramatika, dan struktur teks yang dituturkan kedua calon. (2) Interpretasi debat secara situasional mencakup hal yang terjadi, pihak yang terlibat, dan hubungan yang melatarbelakangi pelibat wacana. (3) Tahap eksplanasi dalam debat Pilkada DKI Jakarta Putaran kedua. Dengan adanya penelitian ini, akan menganalisis debat pilwakotSoloputaran kedua tahun 2020 yang telah ditayangkan di Youtube, dengan menggunakan analisis wacana kritis.

Penelitian ini menggunakan metode deskriptif kualitatif yang bersifat deskriptif. Pendekatan kualitatif lebih bersifat deskriptif, data yang terkumpul berbentuk kata-kata atau gambar sehingga tidak menekankan pada angka dan data yang terkumpul setelah dianalisis selanjutnya akan dideskripsikan sehingga mudah dipahami oleh orang lain (Sugiyono, 2018). Pada penelitian ini, digunakan analisis wacana kritis untuk mengkritisi wacana yang menggambarkan teks dan konteks 
secara bersama-sama dalam suatu proses komunikasi (Eriyanto, 2001). Model analisis pada penelitian ini dengan menggunakan teori fungsional William L Benoit, yang meliputi acclaims, attacks, dan defends.

Teknik pengumpulan data yang digunakan pada penelitian ini adalah studi dokumentasi, yaitu dengan menonton, melihat, dan menulis pokok-pokok terpenting pada siaran langsung debat Pilwakot Surakarta putaran kedua tahun 2020 yang diunggah pada tanggal 3 Desember 2020 dichannel Youtube TATV Solo, dengan judul "Live Debat Pilwakot Surakarta Putaran Kedua / Debat Calon Walikota Solo 2020". Pada tahapan pertama akan diidentifikasi beberapa segmen yang terdapat pada siaran langsung debat Pilwakot Surakarta putaran kedua. Tahapan kedua, peneliti akan mentranskip percakapan pada segmen inti, yaitu sesi debat. Tahapan ketiga akan dianalisis teori fungsional yang ada dalam transkip debat antara pasangan calon nomor urut 1 dan 2. Benoit menyatakan bahwa seluruh percakapan dalam kampanye politik adalah fungsional (Wanfau, 2020). Dengan demikian, tujuan dari adanya kampanye politik ialah memenangkan suara yang ada dengan meyakinkan warga melalui tiga cara kerja teori fungsional, yaitu acclaims atau mengklaim sebagai salah satu bentuk yang dilakukan kandidat untuk menempatkan posisinya, attacks atau menyerang dengan mengungkapkan kekurangan lawan, dan defends atau bertahan sebagai bentuk pertahanan dari serangan lawan. Tahap terakhir adalah menarik kesimpulan. Dengan melakukan tahapan-tahapan tersebut akan membantu penulis untuk mendapatkan informasi yang dibutuhkan pada penelitian ini.

\section{Pembahasan}

Analisis wacana kritis pada debat pilwakotSolo putaran kedua tahun 2020, diidentifikasi dan dianalisis menggunakan teori fungsional menurut William L Benoit, yang pertama adalah, acclaims atau mengklaim, yang kedua adalah attacks atau menyerang dan yang ketiga adalah defends atau bertahan. Tahapan pertama adalah mengidentifikasi segmen yang ada pada siaran langsung debat Pilwakot Surakarta putaran kedua tahun 2020. Dengan durasi 2 jam 30 menit, debat Pilwakot Surakarta terbagi menjadi beberapa segmen, yaitu: 
1. Segmen pertama, penayangan kembali visi misi dari masing-masing pasangan calon.

2. Segmen kedua, menjawab pertanyaan dari moderator dengan tema "memajukan daerah".

3. Segmen ketiga, menjawab pertanyaan dari moderator dengan tema "memajukan daerah".

4. Segmen keempat, menjawab pertanyaan dari moderator dengan tema "menyerasikan pembangunan daerah kabupaten atau kota dan provinsi dengan nasional".

5. Segmen kelima, penayangan aspirasi masyarakat yang elaborasi melalui jawaban masing-masing calon dan merespon tanggapan dari pasangan lawan dengan tema "memperkokoh NKRI dan kebangsaan".

6. Segmen keenam, sesi interaktif atau debat eksploratif dengan tema "memperkokoh NKRI dan kebangsaan, menjalin kolaborasi antar aktor dan memperkuat kewargaan dan kebangsaan".

7. Segmen ketujuh, sesi interaktif atau debat eksploratif dengan tema "kebijakan penanganan, pengendalian, dan pencegahan covid-19".

8. Segmen ke delapan,terbagi menjadi dua sesi. Sesi pertama, saling bertanya antar pasangan calon dengan tema "kebijakan penanganan, pengendalian, dan pencegahan covid-19" dan sesi kedua, penutup atau closing statment.

Pada siaran langsung debat pilwakotSolo putaran kedua terdapat delapan segmen. Sesi inti terdapat pada segmen enam, tujuh, dan delapan yang merupakan debat antar pasangan calon dengan beberapa tema yang sudah ditentukan. Pada penelitian ini akan berfokus pada sesi interaktif atau debat eksploratif yang terdapat pada segmen enam, tujuh, dan delapan. Berikut ini akan dipaparkan hasil analisis debat pilwakot berdasarkan teori fungsional William L Benoit yang meliputi, acclaims atau mengklaim, yang kedua adalah attacks atau menyerang dan yang ketiga adalah defends atau bertahan. Berikut ini adalah dekskripsi data yang menunjukkan adanya acclaims, attacks, dan defends.

\section{Segmen keenam, sesi interaktif atau debat eksploratif dengan tema "memperkokoh NKRI dan kebangsaan, menjalin kolaborasi antar aktor dan memperkuat kewargaan dan kebangsaan".}


1) Paslon nomor urut 2, Bagyo memberikan pertanyaan kepada pasangan calon nomor urut 1 yaitu Gibran-Teguh dengan pertanyaan, "Mas Gibran saya mau tanya, jenengan kan masih muda saya mau tanya, budaya kota Solo ini mau jenengan bawa kemana? Sedangkan jenengan tentang budaya kultur Solo itu kan belum tau-tau bangetlah. Nah ini monggo, coba jawab. Karena gini, ini sudah banyak sekali yang sudah dipimpin oleh pak Teguh yang notabenenya sebagai DPR ini banyak sekali yang di Solo ini sudah seakan-akan lupa ini kota yang seperti apa, budaya nggak ada budayanya. Contoh ya seperti yang menjadi icon kota Solo seperti keraton, seperti itu dan sebagainya. Termasuk hiburan-hiburan untuk orang tua, keroncong, dan wa.. termasuk ketoprak, ini termasuk emm.. nyuwun sewu miris ini." (Attacks atau menyerang)

2) Gibran memberikan jawaban atas pertanyaan yang diberikan oleh paslon nomor urut 2. Jawaban Gibran adalah, "Saya memang masih muda Pak, dan masih harus banyak belajar tapi saya yakin. Ya seperti di segmen-segmen awal tadi Pak, kebudayaan, warisan budaya, paguyuban seni, itu nanti jadi pilar kekuatan dan magnet tersendiri untuk wisatawan untuk datang ke Solo. Makanya saya ingin budayabudaya kita seperti sekaten, grebek sudiro, dll, ini harus dipertahankan. Ini adalah magnet Pak, jadi kita ingin ke depan sudah ada perdanya Pak, perda untuk warisan budaya tak benda. Ini sekarang sudah ada hibah juga Pak, gamelan, pelok, pendro, ke sekolah-sekolah dan kelurahan. Ini memang prnya kita harus mencarikan gurunya Pak, tapi kemarin saya sudah bertemu dengan perwakilan-perwakilan pok darwis dari 5 kecamatan dan nanti kami akan segera eksekusi. Jadi kami dan pak Teguh beda Pak, rembukannya sekarang bukan kalo setelah dilatik. Rembukannya sekarang begitu dilantik langsung eksekusi. Saya tau Pak ini banyak kekurangannya, tapi tujuannya ini adalah sama-sama cari solusi bukan saling menghina, terima kasih." (defends atau bertahan) dan (acclaim atau mengklaim)

3) Paslon nomor urut 2 diberikan kesempatan untuk merespon atas jawaban yang diberikan oleh paslon nomor urut 1. Respon Bagyo mengenai jawaban Gibran adalah, "Saya ini kan orang tua, jadi bukan ini menghina dan sebagainya. Saya selalu minta maaf kepada mas 
Gibran, jadi ini pertanyaan ini kan simple, harus jawab saja gausah pake hal-hal yang sifatnya seperti itu kan jawabannya simpel. Mau dibawa kemana, otomatis kan jenengan jawabnya yang simpel-simpel saja. Fakta kenyataan mas Gibran, saya tuh mau nontonke wayang pakde saya ndak ada, dimana, ketoprak ndak ada. Itu simpel-simpel saja kan pertanyaannya mau dibawa kemana tentang soal budaya, lha budaya saja jenengan sudah hilang masalahnya ya maaf ya bukan saya gini ya, ini fakta saya tuh mau kemana. Pakde saya yang sudah sepuh, saiki ning ndi to ketoprak, itu fakta. Sebelumnya kan yang mimpin juga..."(defends atau bertahan)

4) Paslon nomor urut 1 diberikan kesempatan untuk memberikan pertanyaan kepada pasangan calon nomor urut 2, pertanyaan tersebut adalah, "Karena kita tadi ada kalimat memperkokoh NKRI, maka agar para napiter yang ada di kota Surakarta ini ada beberapa supaya bisa kembali bersosalisasi dengan masyarakat lingkungan sekitar apa yang dilakukan paslon nomor urut 2 untuk program-programnya agar mereka tidak kembalimenjadi teroris atau bahkan radikalis." (Attacks atau menyerang)

5) Paslon nomor urut 2 menjawab pertanyaan yang telah diberikan oleh paslon nomor urut 1, yaitu "Indonesia adalah timur, penuh kultur budaya, yang bisa menyatukan adalah budaya-budaya. Ini yang jangan sampai panjenengan akan istilahnya 'oh ini seorang teroris oh ini seorang, jangan. Itu fatal.' Mengapa menebak seperti itu, itu adalah ketidakadilan di bumi ini pertiwi ini. Itu salah satunya, jangan melihat 'ih itu pencuri, itu maling, jangan.' Itu adalah keadilan yang tidak merata. Ini fakta pak Teguh, jadi selama ini nyuwun sewu betul-betul hal-hal yang sangat miris bahwa kita semua tidak melihat dari hulu hilirnya. Bajo salah satunya nguwongke, mencari penyebab kenapa kok koe nakal, nakal itu adalah karena aku ora ditukokne bapakku tidak dibelikan baju makanya aku nyolong. Jadi jangan melihat sesuatu dari hal-hal yang buruk dulu, inget sunan kalijaga adalah orang-orang yang biasa, didandai, jlumatono, dondomno, seperti saya penjahit, ini adalah sala satu Mas. Jadi saya menyatukan NKRI menyatukan kutho Solo dengan rembuk kutho Solo, salah satunya saya menjahit mendondomi orang-orang yang setelah luka." (defends atau bertahan) dan (acclaims atau mengklaim) 
6) Paslon nomor urut 1 diberikan kesempatan untuk merespon jawaban dari paslon nomor urut 2, "Jadi begini, tidak ada yang kita menghina atau menelantarkan tetapi bagaimana napiter ini bisa kembali ke masyarakat. Kita tidak membeda-bedakan justru programnya apa? Supaya mereka kembali ke masyarakat. Di Penumping ada bestik dan yang jual itu mantan napiter. Nah di lingkungan kita, kita tidak bisa mengetahui dan mereka tidak dikembangkan dengan stimulus kegiatan-kegiatan UMKM, kegiatan yang bisa memunculkan rasa punya pendapatan sendiri, tidak bergantung pada orang lain, maka ini yang harusnya dilakukan oleh calon pasangan." (Attacks atau menyerang)

\section{Segmen ketujuh, sesi interaktif atau debat eksploratif dengan tema "kebijakan penanganan, pengendalian, dan pencegahan covid-19".}

1) Paslon nomor urut 1 dibeirkan kesempatan untuk memberikan pertanyaan kepada paslon nomor urut 2, pertanyaan tersebut adalah, "Saya ingin bertanya masalah penambahan angka covid yang ada di Solo karena ada long weekend kemarin Pak, lalu ada peningkatan covid di Solo. Nah ini Solo sebagai kota yang inovatif dan kreatif apakah nanti program-program yang dari pak Bagyo ini yang sekiranya bisa mengatasi masalah covid di Solo. Kemarin saya baca koran Pak, ini ada teknologi termal kamera, apakah nanti pak Bagyo akan menerapkan teknologi-teknologi seperti ini? Karena 3M saja tidak cukup Pak, harus menggunakan teknologi-teknologi mutakhir agar kota Solo terhindar dari covid." (Attacks atau menyerang)

2) Paslon nomor urut 2 memberikan jawaban atas pertanyaan yang diberikan oleh paslon nomor urut 1, "Ini harus juga adil Mas, yang saat ini ya kenapa mall, hotel-hotel, bank, dan instasi itu betul-betul jaga jarak saja kita mau masuk di BRI itu aja sampai kesulitan, orang dua ndak boleh. Ini ya, ini pertanyaan ya, kenapa di pasar tradisional, di wedangan, jenengan tidak ada yang sifatnya, saya di pasar Kembang, di pasar mana pun nggeh, itu yang namanya wisuh sek, pakek pengukur suhu, itu sama sekali dibiarkan, tau-tau di-lockdown. Hal seperti itu, yang terjadi seperti di gumblekan, itu kan nyuwun sewu, nyuwun sewu ya agak sedikit kurang. Kurang adanya penyuluhan atau di situ kan ada 
pasar, ada lurah pasar,mbok ya diberikan pemahaman atau gimana agar masuk di pasar juga itu juga manusia semua. Panjenengan juga harus kesitu, jangan di atas aja terus. Soalnya saya melihat di pasar penumping mlebu-mlebu dan sebagainya ndak ada. Bajo nanti akan seperti itu Mas, ini yang saya melihat Mas, miris Mas. Tau-tau dia lagi nyambut gawe penak-penak lockdown lagi, tutup lagi, itu juga harus nyuwun sewu, betul-betul kita jaga semua, terutama vitamin Mas. Tulung vitamin disebar ke masyarakat semua."(Defends atau bertahan)

3) Paslon nomor urut 1 diberkan kesempatan untuk menanggapi jawaban, "Ngapunten Pak Bagyo, tadi pertanyaan saya adalah penggunaan teknologi mutakhir Pak, contohnya termal kamera Pak. Jadi yang saya maksud termal kamera itu, kamera yang secara otomatis bisa mengukur suhu badan, itu yang saya maksud Pak. Jadi, ya tadi bapak belum menjawab pertanyaan saya. Saya yakin ke depan teknologi-teknologi seperti ini bisa diterapkan di tempat-tempat kegiatan produktif, seperti yang Pak Bagyo sebutkan di pasar, di kantor, ini harus kita jaga super ketat agar penambahan covid di Solo tidak seperti sekarang. Sekarang pemerintah kota Solo sedang menyiapkan rumah sakit darurat Pak, di wisma atlit di asrama haji Pak. Kita doakan bersama Pak, semoga covid di Solo ini cepat selesai." (Attacks atau menyerang)

4) Paslon nomor urut 2 diberikan kesempatan untuk memberikan pertanyaan kepada paslon nomor urut 1, "Kita tau bersama, khususnya di kota Solo tercinta, terkait dengan covid pasar di-lockdown, perusahan-perusahaan me-lockdown karyawannya dan lain sebagainya. Kita juga tahu bersama, dari calon nomor urut 1 teristimewa beliau Mas Teguh yang selama ini sebagai anggota dewan, sudah berkarya, yang ingin saya tanyakan karena kita juga tau di kota Solo ini banyak cagar budaya yang terjual dan sebagainya. Apa yang akan dilakukan khususnya terkait dengan lockdown di pasar-pasar padahal pasar merupakan penghasil APBD yang luar biasa."(Attacks atau menyerang)

5) Paslon nomor urut 1 diberikan kesempatan untuk menjawab, "Bahwa Solo merangkak sedikit naik angka covidnya, bukan berarti pemerintah tidak melakukan apapun, tetapi justru karena Solo 
menjadi pusat ekonomi di Subosukowonosraten maka yang berkontribusi besar tentang covid itu adalah justru di Subosukowonosraten yang selalu setiap hari, tadi disampaikan penduduk kota Surakarta ini hanya 500.000 jiwa tetapi kalo pagi sampe sore mencapai 2.500 .00 jiwa. Ini potensi yang meningkatkan penyebaran covid di kota Surakarta. Maka dari itu pencegahannya adalah bagaimana seluruh masyarakat Surakarta sadar diri 3M, memakai masker, cuci tangan, dan jaga jarak. Ini yang di masyarakat masih kurang, maka dari itu kami lebih menekankan kesadaran masyarakat itu bisa melakukan 3M yang sudah menjadi protokol kesehatan.(Defends atau bertahan)

6) Paslon nomor urut 2 diberikan kesempatan untuk menanggapi jawaban dari paslon nomor urut 1, "Apa yang disampikan mas Teguh ini sebenarnya sudah dilakukan. Masyakarat sudah melakukan 3M dan sebagainya, namun kita juga tahu semakin lama bukan semakin reda padahal sudah diterapkan seperti apa yang disampaikan mas Teguh sehingga apa, sebenarnya cara apa yang ingin dilakukan karena covid bukan semakin berkurang malah bertambah. Sudah dilakukan tapi masih bertambah, apa yang akan dilakukan bapak ketika nanti mungkin diberikan kesempatan karena selama ini bapak sudah menjabat namun suaranya kok nyaris tak terdengar. Jadi langkahlangkah apa?"(Attacks atau menyerang)

Segmen ke delapan, terbagi menjadi dua sesi. Sesi pertama, saling bertanya antar pasangan calon dengan tema "kebijakan penanganan, pengendalian, dan pencegahan covid-19" dan sesi kedua, penutup atau closing statment.

1) Sesi satu, paslon urut nomor 2 diberikan kesempatan untuk memberikan pertanyaan kepada paslon nomor urut 1, "Langkah konkret apa yang akan dilakukan terkait penanganan covid19?"(Attacks atau menyerang)

2) Paslon nomor urut 1 diberikan kesempatan untuk menjawab pertanyaan tesebut, "Untuk kedepan protokol kesehatan akan erus ditingkatkan, kualitas pelayanan di puskesmas dan RSUD juga harus ditingkatkan karena rumah sakit kita bukan hanya merawat pasien dari Solo saja tetapi juga dari Solo raya mungkin juga sekitar Jawa 
Tengah. Jadi ke depan perlu peningkatan kualitas RSUD dan puskesmas. Kita pastikan tenaga medis punya APD yang lengkap, kita pastikan kamar kita cukup untuk merawat pasien covid. Seperti yang saya bilang tadi, pak walikota sudah menyiapkan rumah sakit darurat di Donohudan, jadi itu kira-kira langkah-langkah yang konkret, dan juga tidak lupa kita harus memupuk rasa gotong royong dan solidaritas melalui program jogo tonggo dan kampung siaga covid. Ini adalah modal kita Pak, yang penting untuk bisa bangkit lagi dari covid. Kita ingin pak RT, pak RW, ibu-ibu penggerak PKK, ibu-ibu posyandu, semuanyabergerak agar covid ini bisa segera selesai di Solo." (Defends atau bertahan)

3) Paslon nomor urut 1 diberikan kesempatan untuk bertanya kepada paslon nomor urut 2, "Ini kan sedang musim penghujan ya Pak, kalau ada banjir otomatis angka covid juga naik Pak. Jadi pak Bagyo sudah bilang ada program sungai bawah tanah Pak, nah ini yang saya tanyakan pembangunan sungai bawah tanah ini anggarannya dari mana? Lalu apakah bapak sudah berkoordinasi dengan balai besar wilayah sungai bengawan Solo, dan perlu saya tekankan lagi pak untuk pembangunan sungai bawah tanah ini kan perlu kita lihat struktur tanah di Solo Pak. Kalau kita lihat, kalau pengen membangun sungai bawah tanah seperti Tokyo, jayantanel itu struktur tanahnya harus didominasi oleh bebatuan padahal di Solo ini struktur tanahnya dari rawa Pak. Nah bagaimana itu nanti Pak kira-kira?"(Attacks atau menyerang)

4) Paslon nomor urut 2 diberikan kesempatan untuk menjawab, "Jenengan jangan mengecilkan, Indonesia itu pinter-pinter Mas. Kenapa bingung, Belanda aja lautnya di atas ini negara di bawah nggak bisa. Tentang anggaran nanti kita ambil 30\% dari APBD, lainnya kita akan bersinergi dengan pengusaha-pengusaha yang ada di kota Solo termasuk masalah kota Solo untuk membangun kotanya sendiri termasuk sungai bawah tanah. Karena itu betul-betul nanti akan berlaku bisa sampai 100 tahun ke depan, daripada hanya sebatas selama ini kan bongkar pasang nanti bangun lagi bongkar lagi, berapa biayanya, 5 tahun sekali pasti mengeluarkan biaya. Kali ini Mas kereta bawah tanah, ini akan memakan waktu 100 tahun lebih, jadi bisahemat anggaran dari setiap 5 tahun sekali anggaran bisa dialokasikan kepada 
UMKM dan sebagainya, jadi itu pengiritan, sekali bangun gitu bersamasama, nanti kita ada konsutan-konsultan, rembuk bareng dengan elemen-elemen yang ada di Kota Solo. Jangan diharap jenengan saja yang punyakonsultan-konsultan Mas, kitapunya juga. Maaf kita wong cilik, tapi yang tidak mendapatkan tempat yang diluar panjenengan, itu ada ekonom-ekonom yang ahli Mas, ada di tempat kita."(Defends atau bertahan)

5) Sesi dua menyampaikan visi misi dan closing statment, paslon nomor urut 2 "Mari kita berdemokrasi yang santun, ngeluruk tanpo bolo, sekti tanpo diaji, menang tanpo ngasarke, pilih nomor 2, coblos. Terima kasih, Bajo, Bajo pasti menang!"(Acclaims atau mengklaim)

6) Closing statment paslon nomor urut 1, "Yang pertama kami bersyukur atas ridho tuhan yang Maha Kuasa, kita sampai di penghujung dan kita masih diberi sehat semuanya, kami ucapkan terima kasih kepada KPU kepada Bawaslu yang telah merencanakan, pengawasan, dan tidak lupa kepada TNI polri yang telah mengamankan jalannya kampanye. Sayayakin KPU sudsh merencanakan dengan baik protokol kesehatan. Terima kasih yang kedua kepada masyarakat Surakata yang telah menerima kami, bluskan virtual, maupun kampanye terbatas, semuanya sudah kami catat akan menjadi program kebijakan GibranTeguh. Yang terakhir kepada DPC kota Surakarta dan juga kepada partai partai pendukung kami ucapkan terima kasih yang telah bergerak bersama dalam rangka menjadi modal politik untuk membangun kota surakarta.Pemilune slamet wargane isoh ngliwet. 9 Desember jangan lupa ke TPS, coblos nomor 1 Gibran-Teguh. Terima kasih."(Acclaims atau mengklaim)

Berdasarkan hasil transkip dari sesi debat publik yang dilakukan oleh kedua pasangan calon, bentuk dari acclaims, attacks, dan defends dapat diuraikan sebagai berikut.

\section{Acclaims atau mengklaim}

Berdasarkan deskripsi data yang telah dipaparkan di atas, kedua pasangan calon secara seimbang melakukan pengklaiman atau pengkauan sebagai salah satu cara untuk meyakinkan pendukungnya. Pasangan calon nomor urut 1 mengklaim dengan adanya budaya-budaya yang ada di Solo dapat menjadi magnet untuk wisatawan, sehingga jikalau 
ia terpilih menjadi walikota Solo akan segera mengeksekusi semua perencanaan yang telah dibuatnya. Gibran juga telah menyatakan bahwa cara kerja paslon nomor urut 1 dan cara kerja paslon nomor urut 2 sangatlah berbeda. Eksekusi yang dilakukan oleh Gibran adalah dengan mencarikan orang-orang yang ahli dalam setiap bidang kegiatan kebudayaan agar dapat semakin berkembang dan menjadi salah satu cara untuk melestarikan kebudayaan itu pula.

Pasangan calon nomor urut 2, yaitu Teguh mengklaim bahwa ia mampu menyatukan kota Solo dan bahkan menyatukan NKRI dengan cara menjahit, atau mendomdomi orang-orang yang setelah luka. Sebagai seorang penjahit, Teguh mengklaim atas kemampuan yang dimiliknya dalam bidang pekerjaan tersebut akan mampu membantunya untuk memenangkan hak suara rakyat kota Solo. Pada pernyataan yang dikemukakan oleh Teguh, mendomdomi merupakan sebuah kata kiasan yang berarti mengobati luka-luka yang dialami oleh orang-orang.

\section{Attacks atau menyerang}

Berdasarkan deskripsi data yang telah diuraikan di atas, pasangan calon nomor urut 1 lebih unggul dalam melakukan penyerangan terhadap paslon nomor urut 2. Hal ini dibuktikan dengan pertanyaan-pertanyaan yang diberikan oleh Gibran lebih terarah dan dapat disampaikan dengan baik. Pada segmen keenam dengan tema memperkokoh NKRI dan kebangsaan, pasangan calon nomor urut 1 melakukan penyerangan denga memberikan pertanyaan kepada paslon nomor urut 2 mengenai program-program yang akan dilakukan untuk para napiter agar mereka tidak kembali menjadi teroris atau radikalis. Sedangkan pada segmen ketujuh dengan tema kebijakan penanganan, pengendalian, dan pencegahan covid-19, Gibran sebagai paslon nomor urut 1, memberikan pertanyaan terkait penggunaan teknologi yang akan dilakukan oleh paslon nomor urut 2 sebagai penanganan covid-19, seperti halnya termal kamera. Selain itu, pada segmen kedelapan dengan tema yang masih sama, paslon nomor urut 1 melakukan penyerangan dengan mempertanyaan program pembangunan sungai bawah tanah yang akan dilakukan oleh paslon nomor urut 2, karena pembangunan sungai bawah tanah membutuhkan pertimbangan dan perisiapan yang harus memadai, mulai dari struktur tanah, anggaran yang akan digunakan, dan lain-lain. 
Pada segmen keenam dengan tema memperkokoh NKRI dan kebangsaan, pasangan calon nomor urut 2 melakukan penyerangan dengan memberikan pertanyaan kepada paslon nomor urut 1 mengenai budaya kota Solo yang akan dibawa kemana. Dapat dilihat pada deskripsi data nomor 1, melalui dialog yang dipaparkan oleh paslon nomor urut 2 terkesan menyudutkan paslon nomor urut 1, karena paslon nomor urut 1 mengklaim bahwa lawannya masih muda dan belum banyak pengalaman yang dimiliki. Sedangkan pada segmen ketujuh dengan tema kebijakan penanganan, pengendalian, dan pencegahan covid-19, paslon nomor urut 2 melakukan penyerangan dengan memberikan pertanyaan mengenai dampak dari lockdown pasar terhadap APBD, karena mengingat bahwa pasar merupakan penghasil APBD yang sangat berpengaruh. Lain halnya pada segmen kedelapan dengan tema yang masih sama, paslon nomor urut 2 melakukan penyerangan dengan memberikan pertanyaan yang mengharuskan lawan untuk menyertakan langkah konkret yang akan dilakukan sebagai penanganan covid-19 yang sedang menimpa negara ini.

\section{Defends atau bertahan}

Dari deskripsi data yang telah dipaparkan di atas, paslon nomor urut 1 lebih unggul dalam melakukan pertahanan. Pernyataanpernyataan sebagai salah satu bentuk defends sesuai dengan serangan yang diberikan oleh lawan. Pada segmen keenam dengan tema memperkokoh NKRI dan kebangsaan, pasangan calon nomor urut 1 melakukan pertahanan dengan mengklaim eksekusi yang akan dilakukan untuk melestaraikan kebudayaan Solo jikalau mereka terpilih. Sedangkan pada segmen ketujuh dengan tema kebijakan penanganan, pengendalian, dan pencegahan covid-19, paslon nomor urut 1 melakukan pertahanan dengan menyertakan data sebagai bukti adanya peningkatan angka covid-19 di Subosukowonosraten yang merupakan pusat ekonomi. Lain halnya pada segmen kedelapan dengan tema yang masih sama, paslon nomor urut 1 melakukan pertahanan dengan mengklaim tindakan yang akan dilakukan sebagai penanganan covid-19, yaitu dengan memperketat protokol kesehatan dan mengingkatkan pelayanan di puskesmas maupun RSUD. 
Paslon nomor urut 2 melakukan pertahanan kurang terarah pada serangan yang dilakukan oleh lawan. Terlihat pada segmen keenam dengan tema memperkokoh NKRI dan kebangsaan, pasangan calon nomor urut 2 merespon atas tanggapan dari pernyataan lawan. Namun, dapat dilihat pada deskripsi data pada segmen keenam di nomor 3, paslon nomor urut 2 melakukan pertahanan dengan mengemukakan pernyataan yang terlalu bertele-tele. Sedangkan pada segmen ketujuh dengan tema kebijakan penanganan, pengendalian, dan pencegahan covid-19, lagi-lagi paslon nomor urut 2 memaparkan pernyataan sebagai bentuk pertahanan yang melenceng dari serangan lawan. Pernyataan yang diberikan oleh lawan berkaitan dengan teknologi yang akan digunakan untuk menangani kasus covid-19, namun pernyataan yang dipaparkan oleh paslon nomor urut 2 sebagai bentuk pertahanan lebih mengarah pada pelaksanaan protokol kesehatan yang akan dilakukan di tempattempat publik. Lain halnya pada segmen kedelapan dengan tema yang masih sama, paslon nomor urut 2 melakukan pertahanan dengan menjawab serangan lawan secara lebih terperinci, yaitu dengan meyakinkan publik dan lawan memaparkan bukti-bukti yang ada.

Berdasarkan hasil transkip dan uraian di atas, dapat dianalisis bahwa pasangan calon nomor urut 1 lebih unggul. Keunggulan dapat diamati dari kemampuan menciptakan pertanyaan, menjawab pertanyaan yang sesuai dengan konteksnya, dan kemampuannya dalam membangun argumentasi saat debat. Pertanyaan-pertanyaan yang dibuat oleh setiap pasangan calon dengan memunculkan data-data yang empiris, akan menujukkan seberapa luas pengetahuan yang dimilikinya.Pada segmen keenam, serangan (attacks) yang dilakukan oleh pasangan calon nomor urut 1 lebih mengarah pada program-program yang akan dilakukan paslon nomor urut 2. Namun, jawaban yang diberikan paslon nomor urut 2 yang merupakan bentuk pertahanan (defends) dirasa tidak sesuai dengan apa yang dipertanyakan dan penyampaiannya terlalu berbelit. Keunggulan lainnya terlihat pada saat paslon nomor urut 1 saat menanggapi pertanyaan dari paslon nomor urut 2, yang menyampaikan beberapa eksekusi yang telah dilakukan, hal ini pun juga termasuk dalam self promotion.Bentuk self promotion di tengah-tengah penyampaiaan argumentasinya ini juga termasuk dalam strategi acclaims yang dibangun 
oleh paslon nomor urut 1. Pada kesempatan merespon tanggapan lawan, paslon nomor urut 2 menggunakan startegi defends yang mana digunakan untuk mempertahankan argumentasinya. Sedangkan pada kesempatan merespon tanggapan, paslon nomor urut 1 menggunakan strategi attacks atau menyerang kembali karena jawaban yang diberikan oleh lawan tidak sesuai dengan apa yang dipertanyakan, dan justru terdapat bentuk self promotion.

Pada segmen ketujuh, paslon nomor urut 1 memberikan pertanyaan yang merupakan bentuk serangan (attacks),mengenai teknologi mutakhir yang akan dikembangkan oleh paslon nomor urut 2. Dari pertanyaan tersebut, paslon nomor urut 1 menyertakan data yang empiris berdasarkan pengalaman atau pengetahuan yang diperolehnya. Lagi-lagi, paslon nomor urut 2 menjawab pertanyaan yang keluar dari konteks. Hal ini menujukkan strategi bertahan (defends) yang dibentuk oleh paslon nomor urut 2 sangatlah kurang.Kemampuan dalam membangun argumentasi pun kurang dilakukan dengan baik oleh paslon nomor urut 2.

Strategi serangan (attacks) yang dilakukan oleh paslon nomor urut 2 pada segmen kedelapan sesi pertama, sudah sangatlah baik yaitu dengan memberikan pertanyaan yang mengharuskan paslon nomor urut 1 memaparkan data-data yang konkret. Dengan memaparkan data yang konkret menjadi salah bentuk defends sekaligus sebagai satu contoh dalam hal penggunaan pengetahuan (knowledge) yang dimilikinya, sehingga menjadi salah satu keunggulan tersendiri bagi paslon nomor urut 1. Pada sesi kedua diberikan kesempatan untuk kedua paslon memaparkan closing statment. Closing statment ini menjadi salah satu bentuk self promotion yang termasuk dalam strategi acclaims. Paslon nomor urut 1 menggunakan sesi closing statment dengan menggunakan bahasa yang tersusun rapi, yaitu dengan menghaturkan terima kasih kepada pihak-pihak yang telah membantu selama proses kampanye dan tak lupa untuk mempromosikan dirinya. Paslon nomor urut 2 menggunakan sesi closing statment hanya dengan menyampaikan jargonnya dan mempromosikan dirinya. 


\section{Kesimpulan}

Debat-debat yang digunakan dalam sebuah forum, termasuk debat pilwakot Surakarta. Debat dalam dunia politik dapat dianalisis menggunakan teori fungsional William L Benoit yang meliputi acclaims atau mengklaim, attacks atau menyerang, dan defends atau bertahan. Dari penelitian ini diperoleh pembahasan pada video debat pilwakot Surakarta yaitu pada tiga segmen yang meliputi, (1) Segmen keenam, sesi interaktif atau debat eksploratif dengan tema "memperkokoh NKRI dan kebangsaan, menjalin kolaborasi antar aktor dan memperkuat kewargaan dan kebangsaan" (2) Segmen ketujuh, sesi interaktif atau debat eksploratif dengan tema "kebijakan penanganan, pengendalian, dan pencegahan covid-19" dan (3) Segmen ke delapan yang terbagi menjadi dua sesi. Sesi pertama, saling bertanya antar pasangan calon dengan tema "kebijakan penanganan, pengendalian, dan pencegahan covid-19" dan sesi kedua, penutup atau closing statment.Berdasarkan hasil analisis penelitian ini, dapat disimpulkan bahwa paslon nomor urut 1 lebih unggul dalam menggunakan strategi acclaims, attacks, maupun defends. Secara keseluruhan, paslon nomor urut 1 dapat mempertahankan argumentasinya dengan kuat pada setiap segmen. Strategi pertahanan argumentasi tersebut merupakan salah satu bentuk defends yang dilakukandengan penyampaian diri yang baik dan bahasa yang mudah dipahami.

\section{Bibliografi}

Ahmad, N. (2012). Manajemen Komunikasi Politik \& Marketing Politik (Cetakan Pe). Yogyakarta: Pustaka Zaman.

Eriyanto. (2001). Analisis Wacana, Pengantar Analisis Teks Media. Yogyakarta: LKis.

Fauzan, U. (2013). Analisis Wacana Kritis Model Fairclough, 5(2).

Fauzan, U. (2014). Analisis Wacana Kritis Dari Model Faiclough Hingga Mils, 6(1).

Istiqomah, R. R. (2004). Kampanye Politik di Televisi sebagai Budaya Populer Ria Rahmatul Istiqomah, 90-96.

Mustofa, A. (2010). Analisis Wacana Percakapan "Debat TV ONE." Universitas Sebelas Maret. 
Pratama, H., Nurcahyoko, K., Hertanto, M. A., Marina, R., Rosyidah, S., \& Kristianto, V. A. (2019). Panduan Debat Kompetitif (Cetakan Pe). Yogyakarta: Erhaka Utama.

Purnaweni, H. (2004). Demokrasi Indonesia: Dari Masa ke Masa. Administrasi Publik, 3 No 2, 1-16.

Simanjuntak, H., \& Salem, L. (2017). Analisis Wacana Kritis Debat Publik Pilkada DKI Jakarta Putaran Kedua Tahun 2020, 1-11.

Sudrajat. (2010). Yunanni Sebagai Icon Peradaban Barat, Vol.III, N, 11-29.

Sugiyono. (2018). Metode Penelitian Kualitatf. Bandung: Alfabeta.

Wanfau. (2020). Analisis Isi Debat Capres RI Pemilu Tahun 2019. IAIN Bengkulu. 